\title{
Evaluation of soil EC mapping driven by manual and autopilot-automated steering systems of tractor on oil palm plantation terrain
}

\author{
Azmi, M.A., Mohammad, R. and *Pebrian, D.E. \\ Faculty of Plantation and Agrotechnology, Universiti Teknologi MARA Melaka, 77300 Jasin Campus, \\ Merlimau, Melaka, Malaysia
}

\section{Article history:}

Received: 23 July 2020

Received in revised form: 8

October 2020

Accepted: 11 December 2020

Available Online: 20

December 2020

Keywords:

Precision agriculture,

Tractor,

Autopilot,

Automation,

Soil sensor,

Steering system

DOI:

https://doi.org/10.26656/fr.2017.4(S5).015

\begin{abstract}
The autopilot-automated steering system is one of today's modern technologies in a tractor's driving system for conducting the operations in farmland. However, further study on the suitability of this steering technology on a particular geographic region is still a necessity. This study evaluated the precision of tractor operations with soil sensor implement using manual and autopilot-automated steering systems on oil palm plantation terrain in Malaysia. A New Holland TD5.75 tractor with 75 hp engine size equipped with a Trimble autopilot-automated steering system pulling a Veris 3100 soil electrical conductivity (EC) sensor was tested in this study. The findings showed that each steering system generated a little different pattern of spatial variability in interpolated soil EC maps. Apart from that, autopilot-automated steering system offered better performances by saving energy expenditure of operator and improving the field capacity of operation. Conclusively, tractor with autopilot-automated steering presented a great suitability for the use in agricultural operations in Malaysia.
\end{abstract}

\section{Introduction}

Mechanization and automation have significantly increased the agricultural production instead of minimized the production costs involved, reduce labour and increased the quality of the products. Nowadays, mechanization and automation are becoming one of the major elements in enhancing agricultural productivity.

Since its development in the first half of the twentieth century, tractors have been the major backbone in mechanizing various agriculture operations, compared to other farm machines. Being a universal prime mover, tractors have proven its superiority in assisting the farmers to perform various stages of an agricultural operation, started from land preparation until transporting the yield products either in-field or from harvesting platform to the packing house. Nowadays the tractor could be said to be an individual part of a farmer's life. Brown (2018) even said that the tractor is like the "heart of a farm" since it is used for many different tasks on a farm.

The revolutionary technology in tractors has transformed farming into today's most sophisticated farming. Tractors have been progressing over the years from gas-powered to gasoline and from single to multiple cylinders. Lately, tractors have been evolving from driver-operated to automatic in line with the advancement of Global Positioning Systems (GPS) modern technology. This automatic system is one part of precision farming tools which has made many changes in farming practices.

Automated driving systems such as autopilotautomated (semi-autonomous) and unmanned (fullyautonomous) mode are becoming classy modes in driving the tractor in an effort of minimizing the driver intervention. The system employs a GPS receiver fitted on the tractor and a computer equipped with special software in the tractor cab to operate the steering system and guide the tractor through the field. Iowaagliteracy (2017) stated that steering a tractor seems easy, especially since tractors are already equipped with all the amenities. Many other benefits make this technology a valuable investment to farmers such as reducing overlap trips in the field. This technology saves costs, has better environmental benefits through precision input application, reduces soil compaction, improves crop yield, efficiency and safety.

According to Lapinski et al. (2016), automatic steering system or autopilot system tractor combines several tools (such as cameras, digital analysis and image 
processing method) and GPS. In general, the system comprised of two major elements which are hardware (various sensor and actuator such as GPS, a steering angle sensor) and software (path planner, a navigation control and steering controller). With high accuracy in the automated steering system, the system enables the farmer to automatically run the tractor throughout the desired path without causing any damage to the vegetation while maintaining a wide range of measurement.

These days the usage of tractors with an autopilotautomated steering system for an agricultural production system is not only limited to the countries of its origin such as the USA, European nations and Japan, but has also spread out to other countries in the world (Hamdan and Pebrian, 2019). Several studies on the use of autopilot-automated tractor in developing countries have been reported in the research literature. Santos et al. (2018), for example, reported the position errors in sowing of peanut in curved and rectilinear routes using autopilot in Brazil. Another similar study was reported by Jahns (1997), who introduced a concept of autoguidance components to minimize the costs of implementation. Easterly et al. (2010) tested the performance of satellite-based tractor auto-guidance using a vision sensor system. Lipinski et al. (2016) compared the tractor implement unit that was operated in the conventional method when the tractor was operated manually and autopilot-steering modes, which relied on satellite navigation.

In Malaysia itself, although the usage of tractors has been drastically increasing to assist agricultural field operation, the usage of tractors with autopilot-automated steering system is still new and is in the beginning stages of the process of commercialization (Hamdan and Pebrian, 2019). In fact, the performance of autopilot tractors in Malaysia's agricultural operations is still rarely published in the research literature. The only attempt was made by Hamdan and Pebrian, (2019), who assessed autopilot-automated tractor suitability on Malaysia's flat terrain conditions.

However, their study was in the preliminary stage and focused only on straight-line accuracy of the autopilot-automated system. Hence, further investigation on the usage of this system would be of prime interest to accelerate in the modernization of technology in agricultural operations through the introduction of autopilot on various field operations.

In relations to the above matter, this study evaluates precisions of tractor operations with soil electrical conductivity (EC) sensor implement using manual and autopilot-automated steering systems on oil palm plantation in Malaysia. According to Grisso et al. (2009), electrical conductivity (EC) is the ability of a material to transmit (conduct) an electrical current. The EC of soils varies depending on the amount of moisture held by soil particles. Sands have a low conductivity, silts have a medium conductiv-ity, and clays have a high conductivity. Consequently, EC correlates strongly to soil particle size and texture. Other than that EC is also useful to determine other soil properties such as waterholding capacity, cation exchange capacity (CEC), depth to claypan or rock outcropping, porosity, salinity and temperature.

This study emphasizes on the qualitative comparisons of the pattern of spatial variability in interpolated soil EC maps as results of tractor operations with soil sensor implement using manual and autopilotautomated steering systems. Human energy expenditure driving manual and autopilot-automated steering systems was also evaluated. The effective field capacity of operation using manual and autopilot-automated steering systems was studied. However, interpretation of the interpolated soil EC maps with laboratory analysis was not included in this study.

\section{Materials and methods}

\subsection{Experimental site and its environment}

This field experiment was carried out at 4.64 ha of oil palm replanting areas in Kempas estate in Jasin district of Melaka state, Malaysia and it is located at latitude $2^{\circ} 15^{\prime} 28.5^{\prime \prime} \mathrm{N}$ and longitude $102^{\circ} 27^{\prime} 46.6^{\prime \prime} \mathrm{E}$. The ground was flat and undulated with an average slope of 9 degrees and ready for replantation oil palm. The ground surface has been cleared from any plant residue such as tree stumps and wood debris. The evaluation commenced in the morning and ended at noon. The weather was bright and fairly cloudy. A total number of 24 tractor passes were set on the test site. Throughout the test period, the recorded daily ambient temperature of the estates was in the range of $24^{\circ} \mathrm{C}$ to $33^{\circ} \mathrm{C}$. Wind speeds ranged from 9 to $16 \mathrm{~km} / \mathrm{h}$, while the relative humidity between 54 to $88 \%$.

\subsection{Equipment and experimental procedure}

A New Holland tractor TD5.75 at 75 horsepower equipped with the autopilot-automated steering system, consisting of Trimble ${ }^{\circledR}$ EZ-Pilot ${ }^{\circledR}$ Steering System and Trimble ${ }^{\circledR}$ FmX ${ }^{\circledR} 2050$ Plus Application (Trimble, 2019) was used in the experiment. The tractor pulled a Veris 3100 soil electrical conductivity (EC) sensor (Figures 1 and 2). The system was operated in two steering modes e.g. manual steering and automated steering system. 


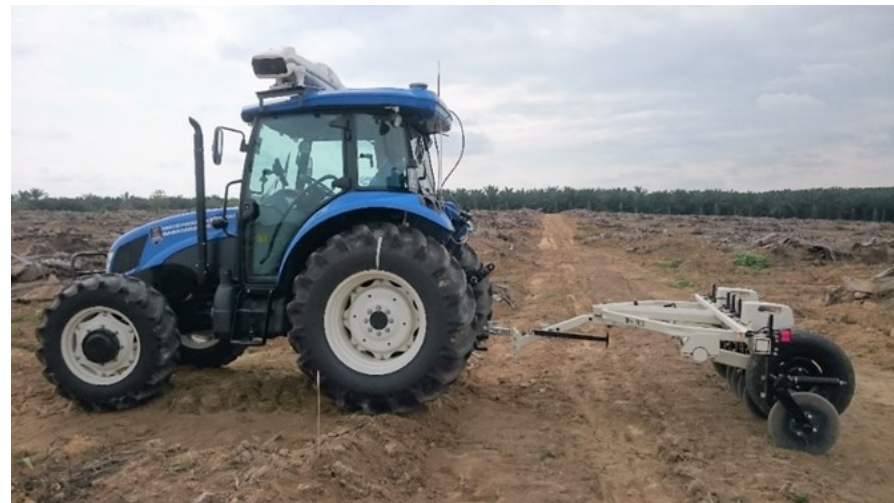

Figure 1. The tractor mounted a Veris 3100 soil electrical conductivity (EC) sensor

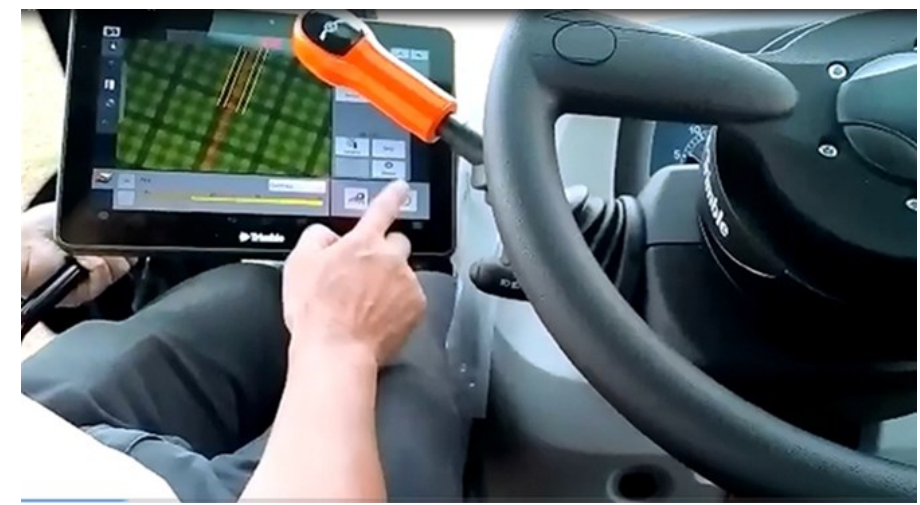

Figure 2. The Trimble $\AA$ EZ-Pilot $\AA$ Steering System and Trimble ${ }^{\circledR}$ FmX ${ }^{\circledR} 2050$ Plus Application on the tractor

Table 1. Specifications of New Holland TD5.75 Tractor

\begin{tabular}{|c|c|c|}
\hline Section of Tractor & Components & Numbers or Specifications \\
\hline \multirow{8}{*}{ Engine } & Number of cylinder/ aspiration/ valves & $4 / \mathrm{TI} / 2$ \\
\hline & Emission level & Tier 3 \\
\hline & Capacity & $3908 \mathrm{~cm}^{3}$ \\
\hline & Rated horsepower-ISO TR 14396-ECE R120 & $56 / 75$ \\
\hline & Rated engine speed & $2300 \mathrm{rpm}$ \\
\hline & Max. Torque - ISO TR14396 & 298@1400 \\
\hline & Fuel tank capacity & $110 \mathrm{~L}$ \\
\hline & Service intervals & $300 \mathrm{~h}$ \\
\hline \multirow{3}{*}{ Hydraulic } & Main pump flow & $36 \mathrm{l} / \mathrm{min}$ \\
\hline & MegaFlow $^{\mathrm{TM}}$ pump flow & $48 \mathrm{l} / \mathrm{min}$ \\
\hline & Steering and services pump flow (Mechanical shuttle/Hydraulic shuttle) & $291 / \mathrm{min}$ \\
\hline \multirow{3}{*}{ Remote valves } & Type & Deluxe \\
\hline & Max. no. rear valves & 3 \\
\hline & Max. no. mid mount valves & 2 \\
\hline \multirow{2}{*}{ Linkage } & Max. lift capacity at ball end & $3565 \mathrm{~kg}$ \\
\hline & Max. lift capacity through the range ( $610 \mathrm{~mm}$ behind ball ends) & $2700 \mathrm{~kg}$ \\
\hline
\end{tabular}

Table 2. Specifications of Autopilot-automated Steering System

\begin{tabular}{|c|c|c|}
\hline Features of autopilot & Components & Specification \\
\hline Brand & Trimble & Steering System and TMX2050 Display Plus Application \\
\hline \multirow{2}{*}{ Steering } & Steering motor & SAM-200 steering motor \\
\hline & Connector & IMD-600 to SAM-200 to CAN power cable \\
\hline \multirow{4}{*}{ System } & DC power & Supplied by TM-200, 27 volts, 3.5 Amps \\
\hline & Processor & $1 \mathrm{GHz}$ quad core \\
\hline & & Primary embedded memory \\
\hline & storage & $32 \mathrm{~GB}$ \\
\hline \multirow{3}{*}{ Mechanical } & Dimension & $312 \times 214 \times 45$ millimeters (plus connectors) \\
\hline & Weight & $2.5 \mathrm{~kg}(5.5 \mathrm{lb})$ \\
\hline & Mount & $4 \mathrm{M} 6$ screws on $75 \mathrm{~mm}$ centers \\
\hline \multirow{2}{*}{ Housing } & Material & Magnesium \\
\hline & Environmental rating & IP55 \\
\hline \multirow{5}{*}{ Connections } & USB ( 1 side facing, 1 rear facing) & USB 2.0 \\
\hline & Ethernet (Via TM-200) & RJ45 connector \\
\hline & CAN (sources 5VDC) & RJ11 connector \\
\hline & Port Expander (optional) & 1 port for $\mathrm{CAN}$ bus, $\mathrm{I} / \mathrm{O}$, and serial \\
\hline & HDMI output & DVI connector \\
\hline \multirow{2}{*}{ Temperature } & Operation & $0^{\circ} \mathrm{C}$ to $65^{\circ} \mathrm{C}$ \\
\hline & Storage & $-40^{\circ} \mathrm{C}$ to $85^{\circ} \mathrm{C}$ \\
\hline \multirow{4}{*}{ LCD display } & Size & $307 \mathrm{~mm}$ \\
\hline & Touchscreen & Protective capacitive touch \\
\hline & Resolution & $1280 \times 800$ \\
\hline & Brightness (adjustable) & 1000 candela $/ \mathrm{m}^{3}$ \\
\hline \multirow{2}{*}{ Front facing camera } & Type & Low light level, color \\
\hline & Resolution & 1.3 Megapixel \\
\hline
\end{tabular}


During the first phase of the experiment, the tractor was carried out with the manual steering system. While operating the steering system manually, the driver was required to steer the steering wheel with his hands. Next, for the second phase of the experiment, the tractor was controlled by the autopilot-automated steering system or driving with hands-free guidance. Detailed specifications of the tractor and autopilot-automated steering system were shown in Tables 1 and 2 .

The identified experimental parameters related to the precision of tractor operations with soil sensor implementation using manual steering and autopilotautomated steering systems were recorded. The said parameters included soil EC maps, errors in positioning accuracy of the automated steering system, the human energy expenditure of operator and field capacity of the operation. The measurements were made in three replications.

Soil EC was mapped with a Veris 3100 soil EC sensor (VERIS, 2019). Detailed specifications of the Veris 3100 soil EC sensor were shown in Table 3. It is a contact sensor measurement that uses electrodes, discs or coulters that contact to the soil to measure the electrical conductivity. During operation, the Veris 3100 sensor was pulled behind the tractor running throughout the field at average speeds of $4.42 \mathrm{~km} / \mathrm{h}$. The data of soil EC was collected at shallow depths $(0-30 \mathrm{~cm})$ and deep depths $(30-60 \mathrm{~cm})$ in the field. The data was displayed with a data logger that would allow the recording of both depths of soil EC measurements. Every information on positions during soil EC application in the field was provided by GPS units.

Table 3. Specifications of Soil EC sensor

\begin{tabular}{|c|c|}
\hline Features of soil sensor & Specification \\
\hline Brand / model & Veris 3100 \\
\hline Overall dimensions: Implement & $\begin{array}{l}\text { Width: } 92.5 ”(235 \mathrm{~cm}) \text {; } \\
\text { t Length: } 96 "(244 \mathrm{~cm}) \text {; }\end{array}$ \\
\hline & Height: $35 "(89 \mathrm{~cm})$ \\
\hline $\begin{array}{l}\text { Weight: basic implement with- } \\
\text { out weight package }\end{array}$ & 1200 lbs. (544 kg) \\
\hline Min. Horsepower Required & $\begin{array}{l}30 \mathrm{hp} \text { (requirements will vary } \\
\text { based on speed, terrain, and } \\
\text { soil condition) }\end{array}$ \\
\hline $\begin{array}{l}\text { Coulter-Electrode Blade Diam- } \\
\text { eter }\end{array}$ & $\begin{array}{l}17 \text { " }(43 \mathrm{~cm}) \text {; thickness } 4 \mathrm{~mm} \text {; } \\
\text { with tapered roller bearings } \\
\text { and cast-iron hubs }\end{array}$ \\
\hline Road Kit & $\begin{array}{l}\text { Stop, turn and clearance light } \\
\text { with } 4 \text { pin flat trailer plug }\end{array}$ \\
\hline Tire size & P205 R75 highway tires \\
\hline Max. Field Speed & $15 \mathrm{mph}(25 \mathrm{~km} / \mathrm{h})$ \\
\hline \multicolumn{2}{|c|}{ 2" ball coupler and safety chain 7,000 lb. rating $(3173 \mathrm{~kg})$} \\
\hline Maximum road speed & $55 \mathrm{mph}(25 \mathrm{~km} / \mathrm{h})$ \\
\hline
\end{tabular}

\subsection{Data analysis}

The ArcGIS 10.3 software with spatial analysis extension was used to generate the spatial variability in interpolated soil EC maps. The qualitative (nonnumerical) method was carried out to analyze the spatial variability in interpolated soil EC maps. Energy expenditure of the tractor operator in kilocalorie per minute was measured using Polar RS800 CX heart rate monitor (POLAR, 2019). In the field experiment, the tractor driver wore the Polar RS800 CX at his hand and H10 Heart Rate Sensor at their chest strap. The recorded data in the sensor was uploaded to the computer to obtain the energy expenditure of the tractor operator in kilocalorie per minute. The field capacity of operation in hectares per hour was obtained by dividing the total coverage area passed by the tractor with the total time taken by this activity. The measurements were made in three replications.

\section{Results and discussion}

Tractor operations with soil sensor implementation using manual steering and autopilot-automated steering systems were able to operate the Veris 3100 soil EC during the field experiment. The operations have successfully measured soil EC at two different depths i.e. shallow depth $(0-30 \mathrm{~cm})$ and deep depth $(30-60 \mathrm{~cm})$ in milli Siemens per meter $(\mathrm{mS} / \mathrm{m})$. The interpolated soil EC maps were divided into three (3) zones of soil EC map i.e. low, moderate and high levels.

At shallow depth $(0-30 \mathrm{~cm})$, generally, the pattern of spatial variability on interpolated soil EC maps as resulted by either autopilot steering or manual steering systems were almost similar. The exception was given with regards to the amount of red colour spots on the soil EC map resulted in a tractor driven with autopilotautomated steering (Figures 3 and 4). In this case, the amount of the red colours on interpolated soil EC map of the autopilot-automated steering were lesser than that of the manual steering. The values of measured soil EC in red colour in the map obtained by a tractor driven with autopilot-automated steering were also different from the manual steering, where the soil EC values of autopilotautomated $(7.05-13.90 \mathrm{mS} / \mathrm{m})$ or slightly higher as compared to soil EC values $(6.37-11.80 \mathrm{mS} / \mathrm{m})$ with the manual steering.

However, at deep depth $(30-60 \mathrm{~cm})$ the pattern of spatial variability on interpolated soil EC map by autopilot-automated steering system was different from that of the manual steering (Figures 5 and 6). Noticeably, the interpolated soil EC map from the sensor pulled by a tractor with autopilot-automated steering showed lesser yellow colour spots and red colour spots than the manual 


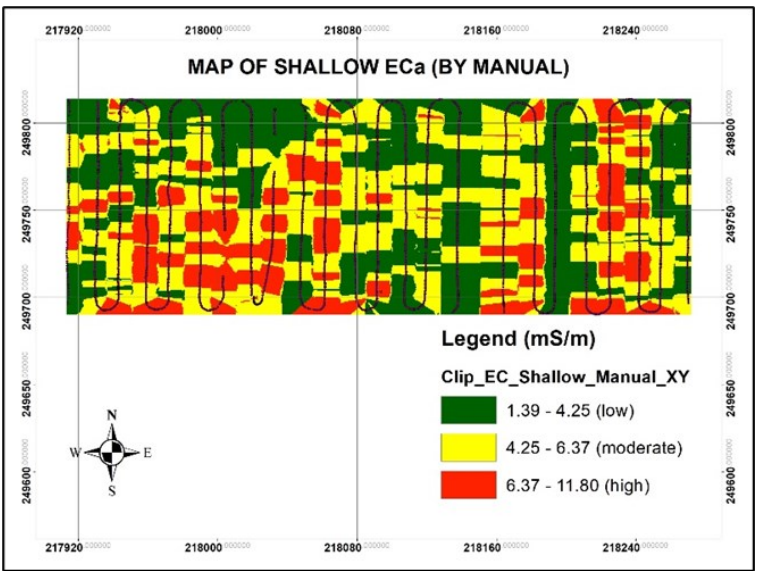

Figure 3. Interpolated soil EC map at shallow depth (0-30 $\mathrm{cm})$ using manual steering system

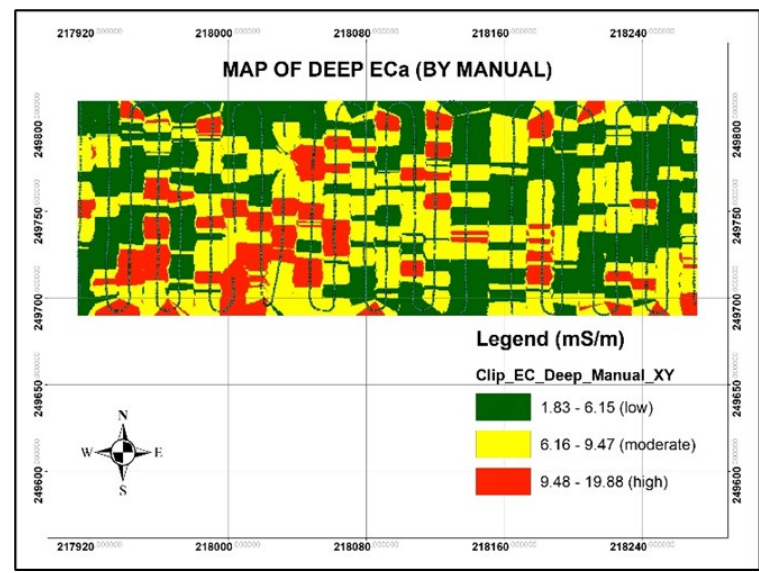

Figure 5. Interpolated soil EC map at deep depth $(30-60 \mathrm{~cm})$ using manual steering system

steering. The readings of soil EC values at deep depth with autopilot-automated steering system also slightly different from the manual ones. The readings of soil EC for autopilot-automated steering system were 1.67-6.02 $\mathrm{mS} / \mathrm{m}$ (low), 6.02-8.79 mS/m (moderate) and 8.79-16.68 $\mathrm{mS} / \mathrm{m}$ (high). While, the readings for the manual steering were $1.83-6.15 \mathrm{mS} / \mathrm{m}$ (low), 6.16-9.47 mS/m (moderate), and $9.48-19.88 \mathrm{mS} / \mathrm{m}$ (high).

Several rationales were taken to explain the differences in the map displayed. The area might have naturally different subsoil characteristics such as moisture conditions at a deep depth. This is consistent with Grisso et al. (2009), the electrical conductivity of soils varies depending on the amount of moisture held by soil particles. Other factors that may explain this situation are soil characteristics such as moisture, temperature, and other changes due to the intensity of sunlight (morning time to noon) by the time the tractor operation was being carried out using autopilotautomated steering. It was bound to happen because there was a time lag between measuring the soil EC using manual steering and autopilot-automated steering system.

Besides that, the tractor operating with two different steering systems also have successfully mapped with $3 \mathrm{D}$

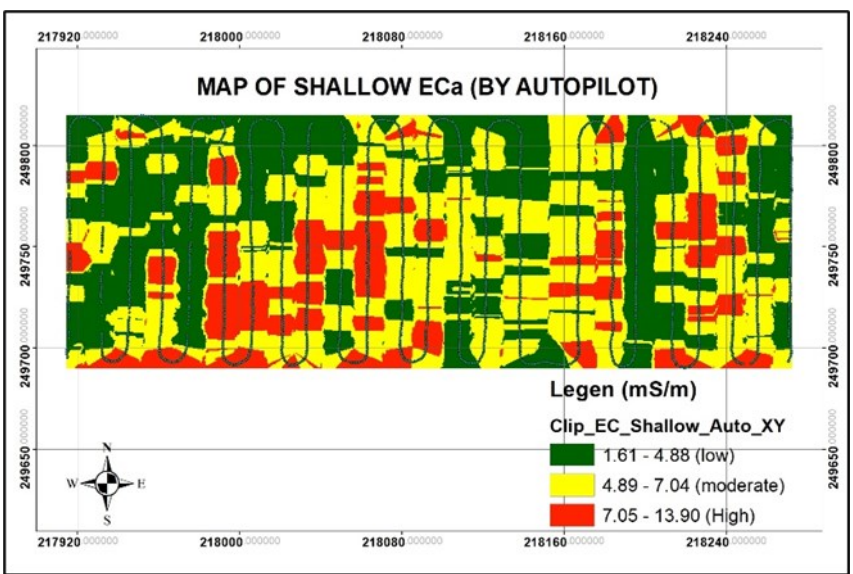

Figure 4. Interpolated soil EC map at shallow depth $(0-30 \mathrm{~cm})$ using autopilot-automated steering system

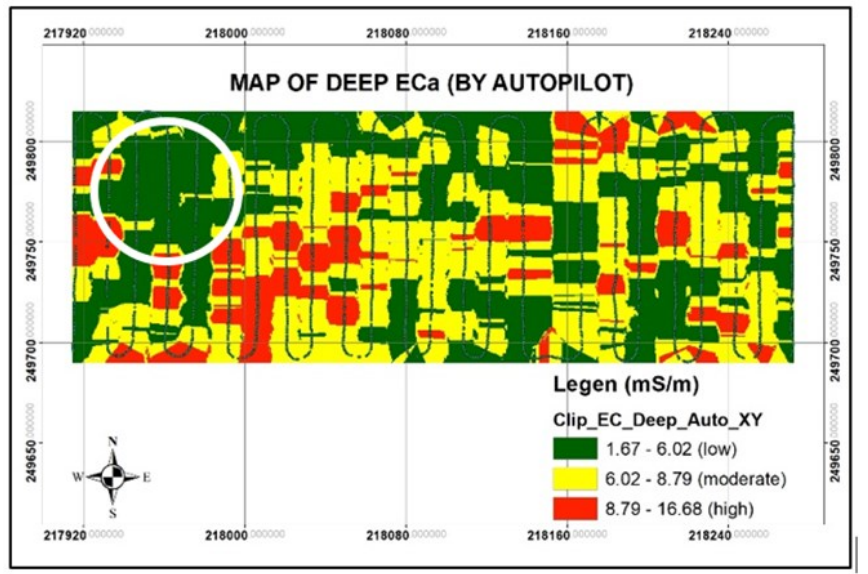

Figure 6. Interpolated soil EC map at deep depth $(30-60 \mathrm{~cm})$ using autopilot steering system

map analysis (Figures 7 and 8). The 3D map analysis showed the elevations of the test site was in the ranges of $20 \mathrm{~m}$ (lowest) and $37 \mathrm{~m}$ (highest). Generally, the pattern of spatial variability in the maps was also similar between tractor operations using manual steering and autopilot-automated steering.

Table 4 summarizes the data of tractor operation with soil (EC) measurements using both steering systems. Descriptively, there are no considerable differences of soil (EC) measurements data read by the tractor operation by using both steering systems. Table 5 shows the energy expenditure of operator and field capacity of tractor operation with soil EC sensor implement using manual steering and autopilotautomated steering modes in the test site area. Tractor operation using autopilot-automated steering system gave $70.67 \%$ lower energy expenditure of operator than that of the manual steering. This indicated that driving the tractor with autopilot-automated steering system was more relaxed as compared to the manual steering, which needs full attention in controlling the steering. The driving technique took more energy of the operator and lead to fatigue during field operation. This is consistent with Murphy (2009) that the current autopilot systems can assist the farmers to complete field operations safely and comfortably, and with less fatigue than ever before. 


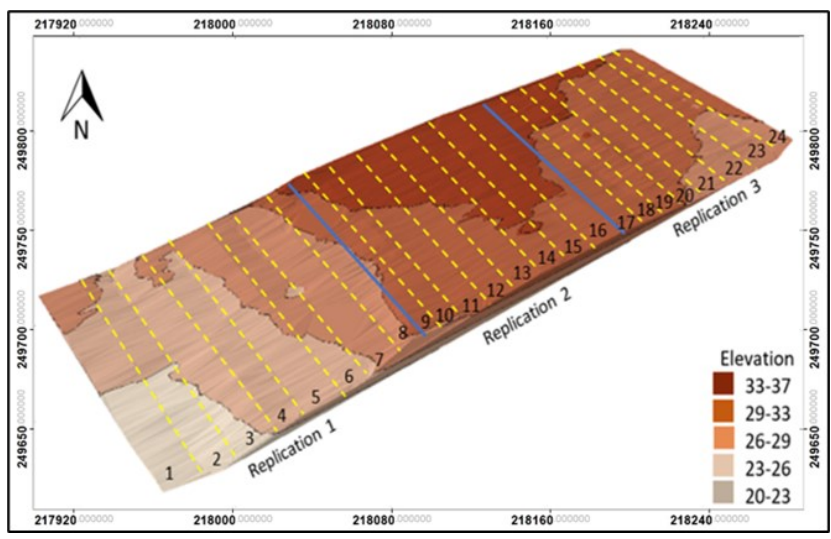

Figure 7. Interpolated 3D map analysis for elevation at the test site using manual steering system

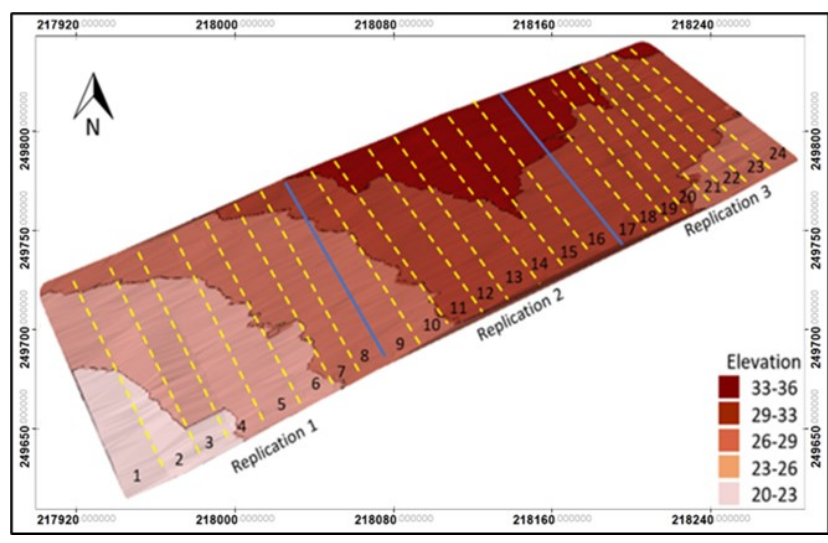

Figure 8. Interpolated 3D map analysis for elevation at the test site using autopilot steering

Table 4. Performance of tractor operation with soil EC measurements using both steering systems

\begin{tabular}{lcccccc}
\hline & \multicolumn{7}{c}{ Steering System } \\
\cline { 2 - 7 } Parameter & \multicolumn{7}{c}{ Manual steering } & \multicolumn{3}{c}{ Autopilot-automated steering } \\
\cline { 2 - 7 } & $\begin{array}{c}\text { Shallow } \\
(\mathrm{mS} / \mathrm{m})\end{array}$ & $\begin{array}{c}\text { Deep } \\
(\mathrm{mS} / \mathrm{m})\end{array}$ & $\begin{array}{c}\text { Elevation } \\
(\mathrm{m})\end{array}$ & $\begin{array}{c}\text { Shallow } \\
(\mathrm{mS} / \mathrm{m})\end{array}$ & $\begin{array}{c}\text { Deep } \\
(\mathrm{mS} / \mathrm{m})\end{array}$ & $\begin{array}{c}\text { Elevation } \\
(\mathrm{m})\end{array}$ \\
\hline No. of points in XY- axis & 3760 & 3485 & 3804 & 3216 & 2996 & 3237 \\
Minimum & 1 & 1 & 22 & 1 & 1 & 20.4 \\
Maximum & 34.8 & 34.8 & 37.3 & 29.3 & 33.8 & 36.2 \\
Mean & 4.94 & 7.03 & 31.36 & 5.55 & 6.67 & 29.95 \\
Range & 33.8 & 33.8 & 15.3 & 28.3 & 32.8 & 15.8 \\
Stand. Dev & 2.9 & 4.79 & 3.35 & 3.11 & 4.02 & 3.21 \\
Variance & 8.41 & 22.9 & 11.22 & 9.66 & 16.16 & 10.3 \\
Coef. Of Variance (\%) & 58.7 & 68.14 & 10.68 & 56.04 & 60.27 & 10.27 \\
\hline
\end{tabular}

Concerning field capacity in completion of the operation in hectares per hour, the autopilot-automated steering system offered $9.06 \mathrm{ha} / \mathrm{h}$ or $21.63 \%$ greater when compared to $7.10 \mathrm{ha} / \mathrm{h}$ of the manual steering. Improvement of field capacity is possibly made by the autopilot-automated steering system since this driving system has better positioning accuracy which can reduce overlapping of passes in the field during the operation. This is in agreement with Siemens et al. (2008), who said that reducing overlaps can improve field capacity of operation. Adamchuk (2008) stated that overlaps can be reduced by the tractor operation using the autopilotautomated system since it was equipped with satellitebased guidance.

Table 5. Comparison of energy expenditure of operator, field capacity of operation using autopilot-automated and manual steering modes

\begin{tabular}{lccc}
\hline \multirow{2}{*}{ Parameter } & \multicolumn{2}{c}{ Steering system } & Difference \\
\cline { 2 - 3 } & Autopilot- & Manual & $(\%)$ \\
\hline $\begin{array}{l}\text { Energy expenditure of } \\
\text { operator }(\mathrm{kcal} / \mathrm{min})\end{array}$ & 1.5 & 0.44 & $(-) 70.67$ \\
Field capacity $(\mathrm{ha} / \mathrm{h})$ & 7.1 & 9.06 & $(+) 21.63$ \\
\hline
\end{tabular}

In general, the results provided a new understanding concerning the performance of manual steering and autopilot-automated steering of a tractor-mounted soil EC sensor on terrain planted with perennial tree crop such as oil palm. The autopilot system of the tractor has proved its ability to map the soil EC and traverse smoothly on oil palm terrain where such terrain is commonly categorized as challenging with many obstacles. Its conditions are very much different from terrains of annual crops or cash crops, which are more well-prepared. Although overlap passes during in-field operations are one of the important parameters in measuring the performance of an autopilot tractor, under the nature of planting rows distance of oil palm of $7.8 \mathrm{~m}$, the investigation on overlap is not applicable for this crop as the working width of tractor-mounted soil EC sensor was only $2.25 \mathrm{~m}$ or much narrower than the planting rows distance of oil palm. This system only measured the soils that are closely aligned with planting rows, hence, no overlap measurement.

Even though the scope of this study does not apply to the overlapping investigation, however, as mentioned earlier, the implementation of the automated steering system in planting and tillage operation had been known globally. Overlap passes became one of the parameters that have been studied. Such as a study by Lapinski et al. (2016), who reported that the mean actual working width of tillage implement with autopilot-automatic steering mode was in the range of $6804 \mathrm{~mm}$ to $6815 \mathrm{~mm}$, which was $3.51 \%$ to $3.67 \%$ wider than $6565 \mathrm{~mm}$ of the manual steering mode. Besides that, mean overlaps of working width of tillage implement with autopilot-automatic 
steering were $16 \mathrm{~mm}$ to $60 \mathrm{~mm}$, which was $94.22 \%$ to $78.34 \%$ narrower than $277 \mathrm{~mm}$ of the manual steering mode. Meanwhile, Kayacan et al. (2014) reported mean values of error for the tractor and trailer was 3.61 to 6.44 $\mathrm{mm}$ for a straight-line trajectory and 41.52 to $49.78 \mathrm{~cm}$ for a curved path. Santos et al. (2018) found the maximum parallelism error of peanut sowing by autopilot steering were 8.75 and $5.22 \mathrm{~cm}$ in the curved and rectilinear path, respectively, while $11.10 \mathrm{~cm}$ and $4.05 \mathrm{~cm}$ for the maximum execution errors. Parallelism errors were taken employing the distance between the lines executed by the tractor-seeder assembly, whereas, execution errors were found based on the difference between the previously projected lines and the lines executed by the tractor.

\section{Conclusion}

The precision of operation of tractor-mounted with soil EC implement using manual steering and autopilotautomated steering system on oil palm replanting area in Malaysia was successfully evaluated. Generally, the pattern of spatial variability on interpolated soil EC maps at shallow depth $(0-30 \mathrm{~cm})$ using manual steering and autopilot-automated steering is almost similar. However, there were differences between the pattern of spatial variability on interpolated soil EC map at deep depth (30 $-60 \mathrm{~cm})$ driven by autopilot steering and manual steering. The tractor operation using autopilot-automated steering system showed better performances in saving human energy expenditure of operator and increasing field capacity of operation. Conclusively, tractor with autopilot steering system has proved to be able as one of an alternative method for driving a tractor in agricultural operations in Malaysia.

\section{Conflict of interest}

The authors declare no conflict of interest.

\section{Acknowledgments}

The authors are very grateful to the Sime Darby Plantation Berhad for providing the study area for this research project.

\section{References}

Adamchuk, V.I (2008). Satellite Based-Auto Guidance. p. 1-6. Lincoln USA: University of Nebraska,

Easterly, D.R., Adamchuk, V.I., Kocher, M.F. and Hoy, R.M. (2010). Using a vision sensor system for performance testing of satellite-based tractor autoguidance. Computers and Electronics in Agriculture, 72(2), 107-118. https://doi.org/10.1016/ j.compag.2010.03.004
Jahns, G. (1997). Automatic guidance of agricultural field machinery presented at the Joint International Conference on Agricultural Engineering and Technology exhibition, Bangladesh, 1997. Retrieved on January 20, 2019 from http://www.fal.de/ $\square$ jahns/ papers.html.

Grisso, R., Alley, M., Holshouser, D. and Thomason, W. (2009). Precision farming tools: Soil electrical conductivity. Virginia Corporative Extension. Virgina, USA: Virginia Polytechnic Institute and State University.

Hamdan, M.H. and Pebrian, D.E. (2019). Preliminary assessment on the potential for use of an autopilot tractor on Malaysia's flat terrain. The Planter, 95 (1115), 97-104.

Iowaagliteracy. (2017). Why do they do that? - Selfsteering Tractors. IALF (Iowa Agriculture Literacy Foundation). Retrieved on August 18, 2019 from Iowaagliteracy website: https:// iowaagliteracy.wordpress.com/2017/04/28/why-dothey-do-that-self-steering-tractors/.

Kayacan, E., Kayacan, E., Ramon, H. and Saeys, W. (2014). Learning in centralized nonlinear model predictive control: application to an autonomous tractor-trailer system. IEEE Transactions on Control Systems Technology, 23(1), 197-205. https:// doi.org/10.1109/TCST.2014.2321514

Lipinski, A.J., Markowski, P., Seweryn, L. and Pyra, P. (2016). Precision of tractor operations with soil cultivation implements using manual and automatic steering modes. Biosystem Engineering, 145, 22-28. https://doi.org/10.1016/j.biosystemseng.2016.02.008

Brown, M. (2018). Smart Farming-Automated and Connected Agriculture. Retrieved on September 22, 2019 from Engineering website: https:// www.engineering.com/DesignerEdge/

DesignerEdgeArticles/ArticleID/16653/Smart-

FarmingAutomated-and-Connected-Agriculture.aspx

Murphy, D. (2009). Agricultural Vehicle Autopilot Roll Over Risk Assessment System. US 8275516B2. United States Patent Office.

POLAR. (2019). H10 heart rate sensor. Retrieved on January 07, 2019, from POLAR website: https:// support.polar.com/en/support/

H10_heart_rate_sensor.

Santos, A.F.D., Correa, L.N., Gírio, L.A.S., Paixão, C.C.S. and Da Silva, R.P. (2018). Position errors in sowing in curved and rectilinear routes using autopilot. Engenharia Agrícola, 38(4), 568-576. https://doi.org/10.1590/1809-4430-

eng.agric.v38n4p568-576/2018

Siemens, J., Bowers, W. and Holmes, R.G. (2008). 
Machinery Management. Illinois, USA: Deere and Company.

TRIMBLE. (2019). Trimble Autopilot ${ }^{\mathrm{TM}}$ Automated

Steering. Retrieved on July 17, 2019 from TRIMBLE website: https://agriculture.trimble.com/ product/autopilot-automated-steering-system/

VERIS. (2019). Soil EC 3100. Retrieved on January 4, 2019, from VERIS website: https:// www.veristech.com/the-sensors/v3100. 